\title{
The "use" of an electronic resource from a social network analysis perspective
}

\author{
Marie R. Kennedy, David P. Kennedy
}

\begin{abstract}
This article employs social network analysis as a mechanism to bridge the typical ways of talking about usage statistics and to provide a context-specific perspective about the mediated use of electronic resources. The article reports on an analysis of data gathered at the Loyola Marymount University (Los Angeles, California) about standard usage statistics as well as library Information Desk encounters during which an electronic resource is mentioned. Our analysis demonstrates that e-resources are suggested and used in concert; there are central resources that are mentioned together, instead of a single e-resource being suggested alone to resolve a given information need. We also learned that half of the available electronic resources are not suggested once during the year analyzed. The conceptual results of this work support the use of social network analysis in examining other relational aspects of library work. Practical results are reported as well, most notably the use of more than one resource to fulfil an information need.
\end{abstract}

\section{Introduction}

Libraries have an interest in measuring the use of their collections of electronic resources for a variety of reasons. Librarians review usage statistics to inform collection development decisions, such as to:

justify purchases; cancel subscriptions; aggressively market less used resources, upgrade existing resources, aid in strategic planning, [etc.]

(Tucker, 2009, 52)

\section{Author}

Marie R. Kennedy is the Serials \& Electronic Resources Librarian at the William H. Hannon Library of the Loyola Marymount University.

Email: marie.kennedy@1mu.edu

David P. Kennedy is a social scientist at the RAND Corporation and professor at the Pardee RAND Graduate School.

Received 01 May 2014

Accepted 02 October 2014 
In addition to reviewing the data for management decisions we can reconceptualize the purpose of usage statistics to determine if we are satisfying the needs of our patrons during their research process. There are a few approaches to recording how often electronic resources have been used by patrons and these approaches have strengths and weaknesses. One of the primary weaknesses of these standards is the lack of information about how patrons identify certain resources to access: the statistics represent "the found" but not "the finding."

The purpose of "the finding" is for the patron's ultimate use. The field of information and library science has explored the process of information seeking over decades (for example, Bates, 1989; Dervin, 1977; Kuhlthau, 2004; Wilson, 1981). This article attempts to insert the concept of "finding" into the current measurement statistics that represent "the found," to better conceptualize the path a patron may take to resolve an information need that uses an electronic resource as the mechanism for resolution. The artefacts of this path may be viewed via the traditional usage statistics of those electronic resources ("the found") but may be better supported by inserting a view on the finding process through expert mediation. This mediation process may explain some of the gaps evident between the two major types of usage statistics counting mechanisms.

\subsection{Two major types of electronic resources usage counting mechanisms}

Mainstream electronic resources from major publishers or aggregators to which a library subscribes employ the COUNTER Code of Practice to measure usage, and as a result the amount of use of those resources can be compared reliably. It is clear that libraries desire to have the most reliable usage statistics and so prefer to use COUNTER when available.

Project COUNTER is an international standard of describing the usage of an electronic resource (COUNTER, 2014). The scope of what is counted and how it is counted has both broadened and become more granular over the ten years of its existence. Initially released to count the number of times an article from an electronic journal was downloaded, it has now embraced databases and e-book formats, and with the latest release (Release 4), multimedia resources. The reports show the name of the resource in one column and the corresponding counts per month in subsequent columns, followed by a totals column. The statistics are easy to download into Excel for further manipulation, and are often used to create costper-use data. The COUNTER standard is a familiar one among librarians and is the counting mechanism most often used in the evaluation of electronic resources. There are electronic resource management systems that can ingest the data automatically, using a protocol by the National Information Standards Organization called Standardized Usage Statistics Harvesting Initiative (SUSHI) (NISO, 2013).

Although usage statistics are complex and meaningful, they do not tell us all that we desire to know about the use of an electronic resource:

Both Project COUNTER (Counting Online Usage of NeTworked Electronic Resources) and the Standardized Usage Statistics Harvesting Initiative (SUSHI) 
of the National Information Standards Organization (NISO) lack a definition for a usage.

(Grogg and Fleming-May, 2010, 8)

The second major method of counting usage relies on data from proxy servers. When libraries subscribe to or purchase an electronic resource they are compelled by a license agreement to restrict the use of the resource to authorized patrons. To accomplish this, libraries will often require that patrons prove their affiliation by authenticating through a proxy server. In the proxy server configuration table there are entries for each of the resource host URLs, and a count is made every time a patron clicks on the main URL of that resource to begin a search (usually called a "hit"). The reporting structure is similar to COUNTER in that the reports show the name of the resource in one column and the corresponding counts per month in subsequent columns. These statistics are usually generated ad hoc by querying the system, and are usually available to download to Excel for further manipulation.

\section{Literature review}

As researchers begin to define their own research tasks they are likely to browse around in several databases, evidenced by a high number of resulting proxy server hits. When we compare the proxy server statistics to COUNTER statistics we see a decidedly smaller count, and believe that this accounts for the researchers having progressed from the information seeking phase of identifying a problem, formulating a search query, followed by any iteration of the browsing process, and have ultimately selected articles to download, beginning what Marchionini calls their evaluation and use phase (Marchionini, 1995).

Since Dervin's influential work (Dervin, 1977), models of information seeking have been primarily human-centered. We agree with her assertion that:

the assessment of library activities within the context of a communication model results in assessments focused on how libraries can help people inform themselves, create their own orders, and establish their own understandings.

(Dervin, 1977, 29)

Marchionini provides such a model of a person's information seeking in an electronic environment, describing the components of a search system as a backand-forth interaction between a single information seeker, an interface (conceptual, physical), and a database (content, container) (Marchionini, 1995, 39). This research highlights an expansion of that model to include another person, an expert guide, working in tandem with the information seeker (see Figure 1). Using Wilson's model, the expert guide in Figure 1 would be referred to as "other people," noting that an information seeker may reach out to a person for assistance during the seeking, using an iterative process (Wilson, 1981, 4). 
There is wide acceptance of this expert-mediated model in the library literature, related to collaborative / consultative information seeking (see Talja (2002) for an excellent history of the literature in this area). Those studies, whether they focus on the individual searcher or group searchers (a collaborative model), have an interest in the relationship between the searcher and expert, or on research within a domain.

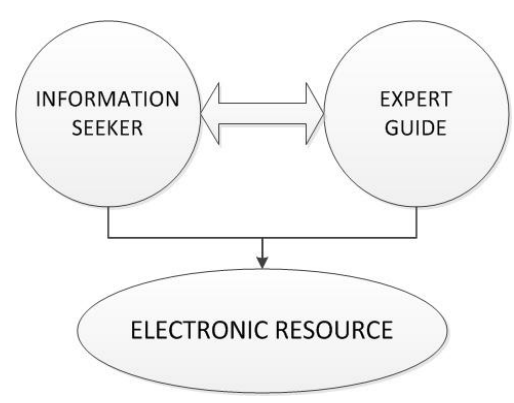

\section{Figure 1: Expert-mediated model of information seeking.}

This research focuses on the relationship between the expert and the electronic resource s/he may suggest in response to an information seeker; in this way the research makes a unique contribution to the literature.

It is informative to have another conceptual perspective that is related to the one illustrated in Figure 1. Contractor et al. (2011) describe the concept of a multidimensional network, in which the traditional person-to-person interaction includes a non-human actor, such as an electronic resource. The interaction they describe mimics the information pathway described in Figure 1, but does so from a social network analysis perspective, which is what we introduce in the next section of this article.

We understand that the theoretical approaches to information retrieval, as described in in Dervin and Nilan's 1986 ARIST chapter (Dervin and Nilan, 1986), have traditionally been problematic. This research responds to their call for a paradigm shift by focusing on the sense-making approach (situation-gap-use). Wilson noted in 1999 that a critique of research about information seeking is that:

researchers have not built upon prior research in such a way as to cumulate a body of theory and empirical findings that may serve as a starting point for further research

(Wilson, 1999, 250)

In this article we hope to describe how the social network approach can contribute to existing models as well as suggesting further research which could employ the approach. 


\subsection{The introduction of an alternative counting mechanism}

The two counting mechanisms described in section 1.1 count single interactions between an information seeker and an electronic resource. We suspect that including a third counting mechanism, one in which we can view a social interaction, may provide a better understanding of how an information seeker makes the decision to select one electronic resource from the wealth of options in an academic environment. We turn our attention, therefore, to another data set available to us at the William H. Hannon Library of the Loyola Marymount University which provides data about interactions between an information seeker and an expert guide, during a mediated search. A commercial software tool, Gimlet (Gimlet, 2014), is used to record a summary of expressed information needs from patrons and the responses of expert guides, who make suggestions about relevant electronic resources available in the library collection.

In the past, interactions at a service point in a library might be logged on scrap pieces of paper, with hash marks indicating the kind of question asked or answered (directional, reference, technical, etc.). Libraries would log each interaction separately; although a person at the service point may interact with the same patron over time, the data entered were transactional, rather than relational. Commercial systems, such as Gimlet, are now available to record such data. The library of Loyola Marymount University has customised this software to collect data appropriate for its academic library.

The following data are manually entered into the Gimlet system:

- the initials of the person entering the transaction;

- where the interaction with a patron took place (Information Desk, ...);

- the duration (less than 5 minutes, 16-30 minutes...);

- format (in person, email...);

- questioner (student, faculty, unknown ..);

- question type (reference, technical, policy, directional);

- difficulty;

- the question asked;

- the answer given.

The person entering the details of the interaction then selects one or more tags to describe it generally, from a series of descriptive statements that the Reference Department has defined, such as "Known Item Request," "Printing" or "Wireless". The date, day of week, and time are automatically entered, but can be 
manually adjusted. See Figure 2 for a screen shot of the customized data entry interface.

Ideally the person staffing the service point enters the description of the interaction immediately after it is completed, while the interaction is still fresh in his / her memory. The data about the interaction are subject to the bias of the person entering the data. One-on-one training about consistent data entry has been provided and a reference guide about categorising interactions is available at the Information Desk, which is a main service point for the LMU library. Gimlet statistics can be viewed within the system reports or may be exported to Excel for further manipulation.

The purpose of using a tool such as Gimlet is to document the wealth of personal interactions that occur at the Information Desk. The main reason for using this tool is to guide library management decisions about staffing and library opening hours.

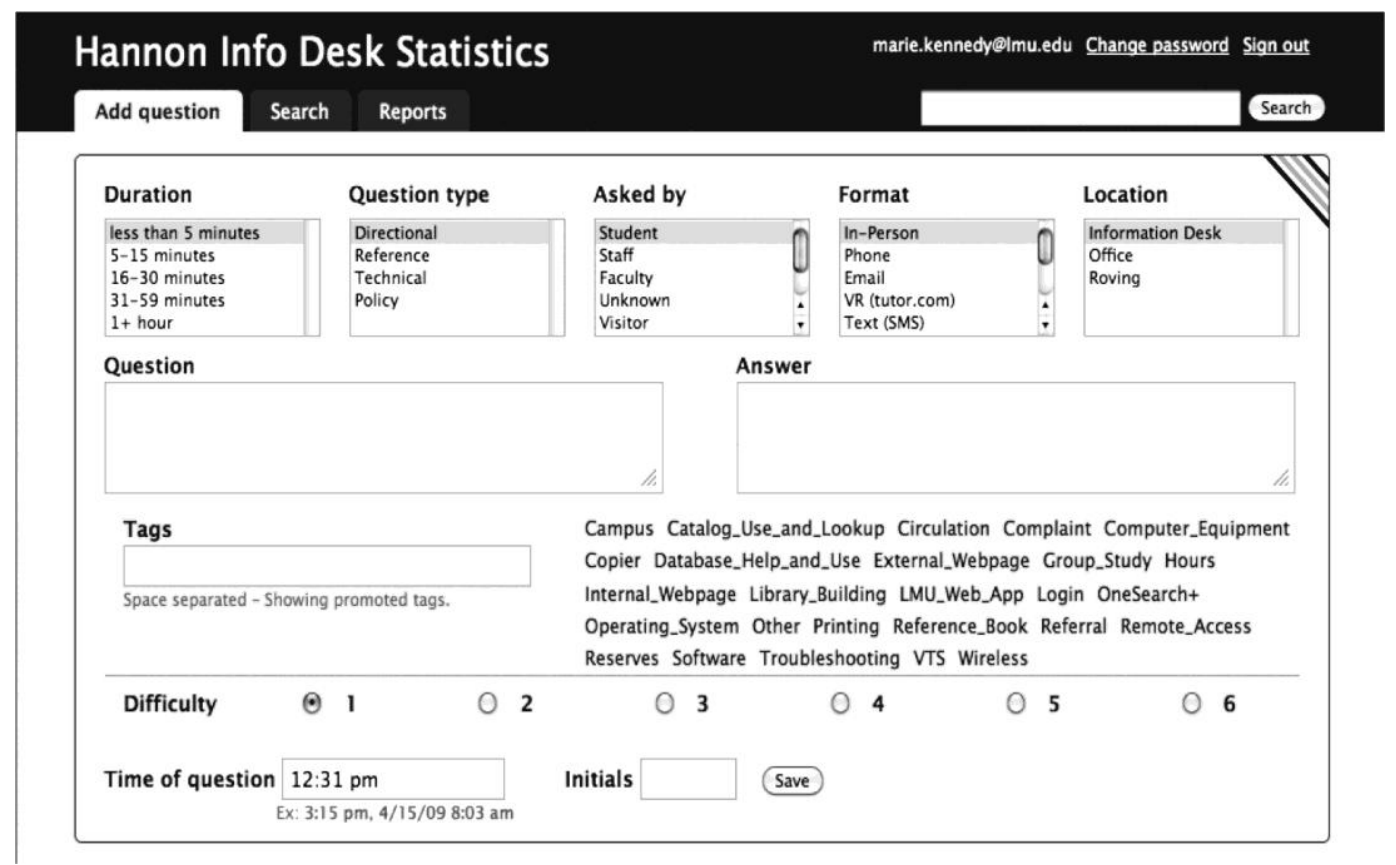

Figure 2: Gimlet data entry interface.

In this research, we examine the Gimlet data about reference interactions during which an electronic resource is mentioned. There are no other data collection mechanisms currently in place at the university which record this kind of data. By transforming the logged information from the Gimlet statistics and conducting a social network analysis, we can begin to see the influence an Information Desk staff person may have in assisting the patron in the selection of a resource to find relevant content. 


\section{Methods}

We describe and compare three measurements of electronic resource usage. The first two are commonly known: COUNTER and proxy server statistics. The third is a novel approach to describing usage, counting the suggestions of electronic resources from Information Desk staff to patrons, logged in Gimlet. For this research we use counts ranging from 1 June 2011 to 31 May 2012.

We began by downloading and aggregating usage statistics from the majority of the subscribed electronic journals at Loyola Marymount University, compiling them in Excel. We then downloaded and aggregated usage statistics for electronic resources accessed through the library's proxy server, also compiling them in Excel. Finally, we transformed qualitative entries from Gimlet into quantitative data in order to conduct a social network analysis, using the software UCINET (Borgatti, Everett and Freeman, 2002).

\section{Findings}

\subsection{Data transformations}

\subsubsection{COUNTER JR1}

We chose to download the COUNTER JR1 reports (COUNTER, 2008), which provide the number of successful full-text article requests by month and journal. The number of article downloads during the month of April 2012 was irregular and so for this research an average use during that month is reported. The average was created by using the last four years of usage during that month. These statistics are typically reported in bar chart format, as is shown in Figure 3. The total number of full-text article downloads by patrons at Loyola Marymount University (LMU) for the year was 461,180.

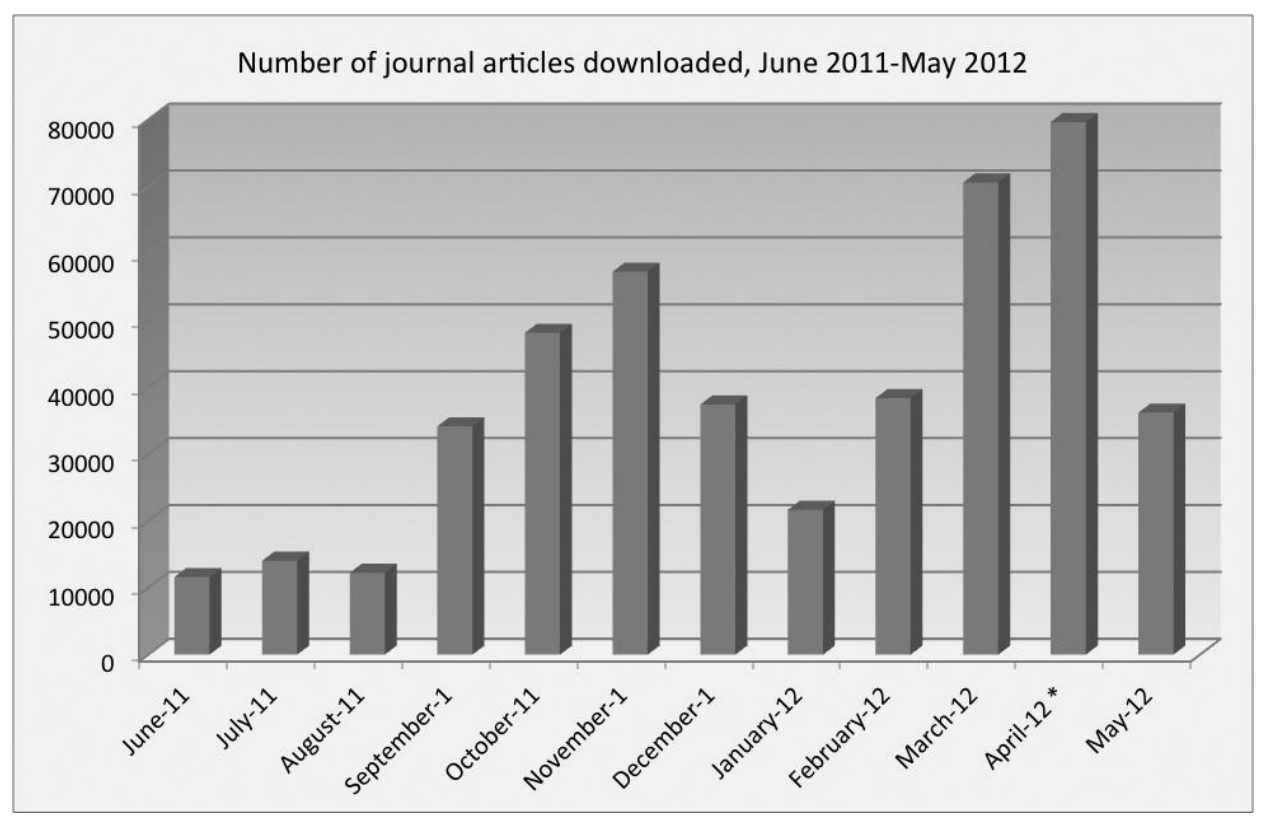

Figure 3: Article downloads. 


\subsubsection{Proxy server}

We downloaded and aggregated usage statistics for all uses of electronic resources through the proxy server at LMU. These statistics are typically reported in bar chart format, as is shown in Figure 4. The total number of "hits" by patrons at LMU for the year is $21,262,269$.

Figure 5 uses a line graph to compare the usage of electronic resources recorded in COUNTER JR1 data and in proxy server data for the time period of one year. The top line in the figure shows the proxy server statistics. This line represents the total number of times a patron clicked on a link to access an electronic resource. The bottom line in the figure shows the COUNTER JR1 data. This line represents the number of full-text downloads from e-journals. Full-text downloads of ejournal articles represent only 2 percent of all the hits of the library's electronic resources. It is clear that there is a wide gap between a hit and a download, although the comparison of the two metrics is not perfect, as the proxy server statistics includes the number of times a patron clicked on any kind of electronic resource (such as database, an e-book, or an e-journal) and the COUNTER JR1 data only represent the number of full-text downloads of an e-journal article.

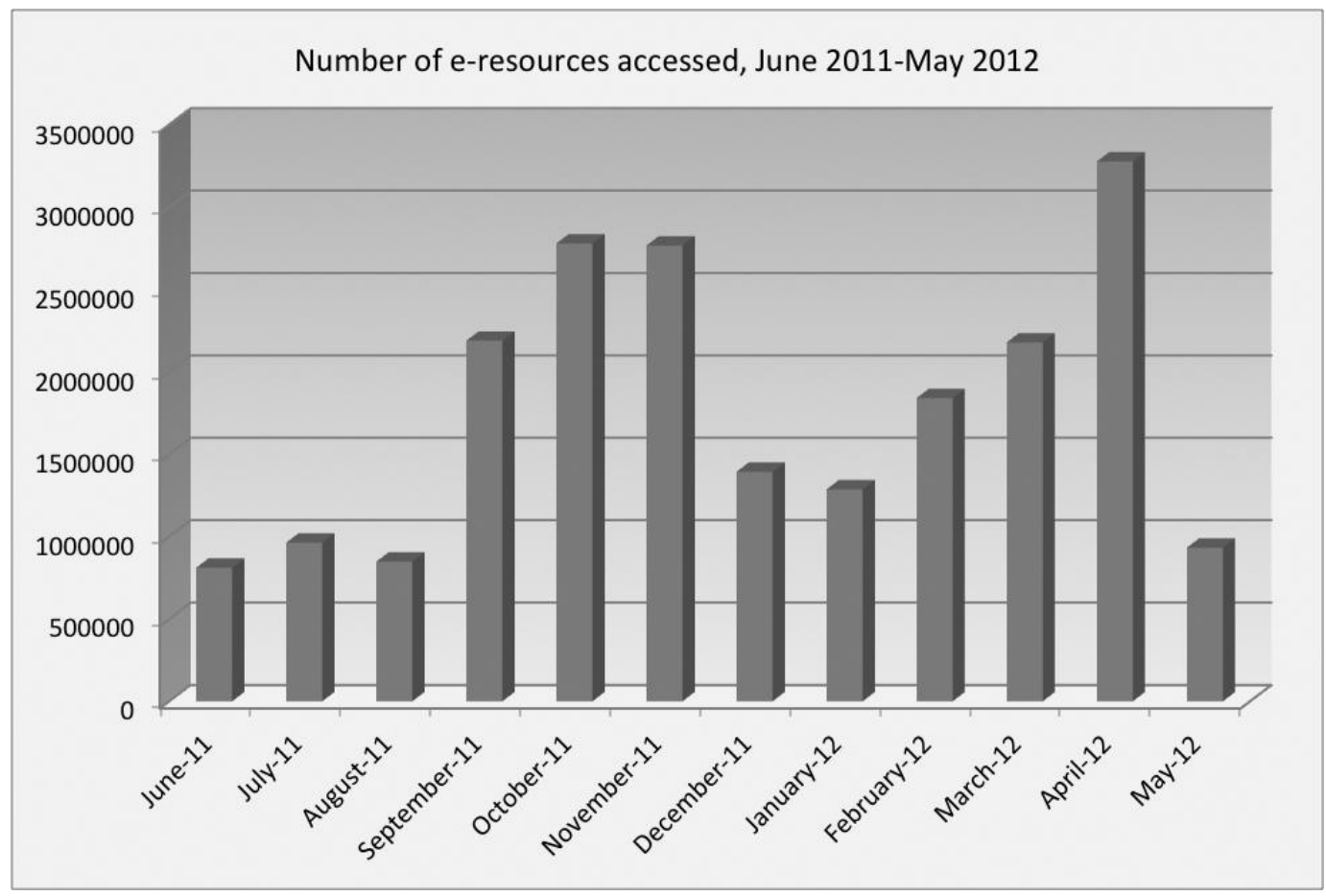

Figure 4: Proxy hits. 


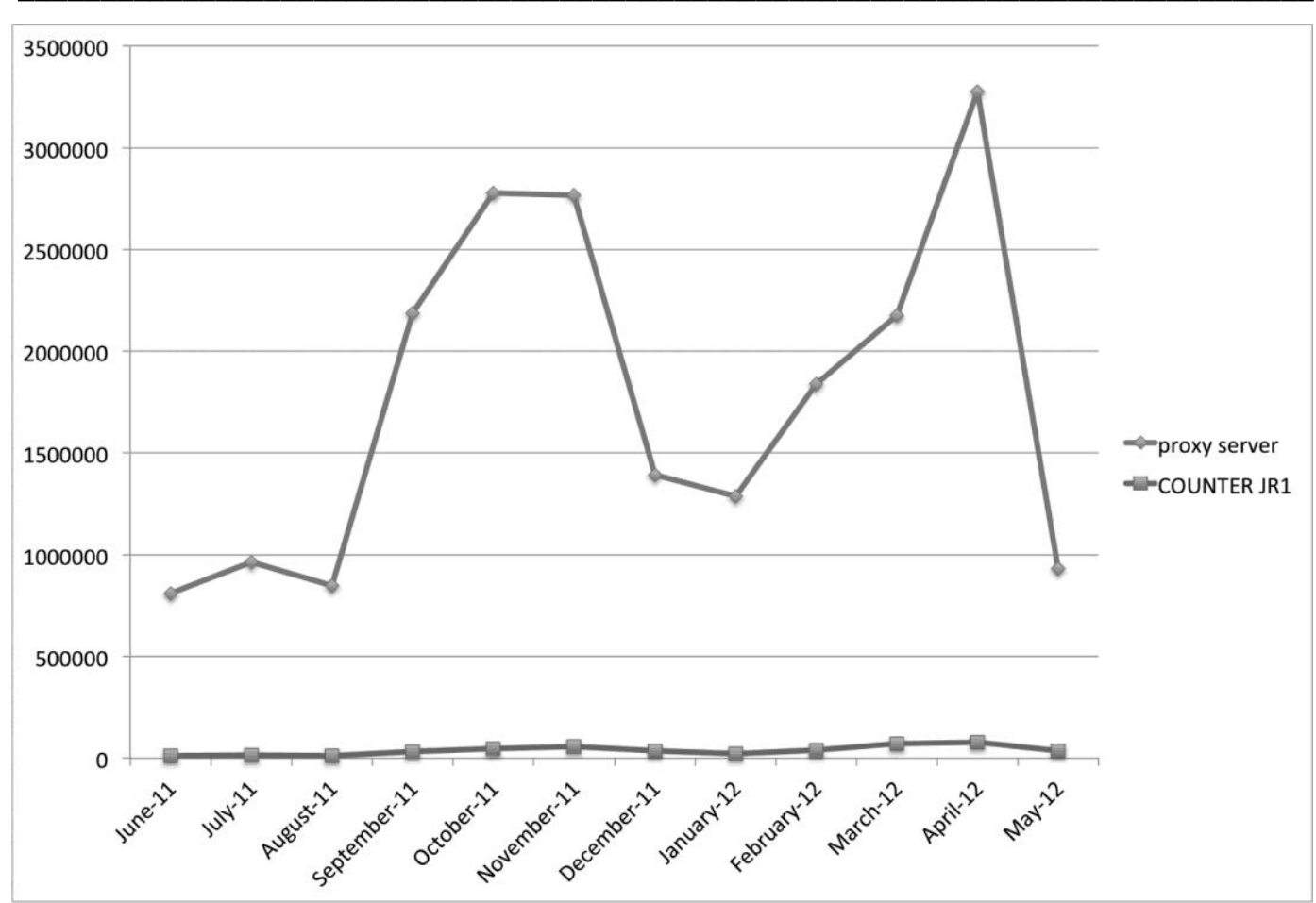

Figure 5: Downloads-proxy comparison.

We suspect that what inhabits this space in the graph between the proxy server line and the COUNTER line is part of the information seeking process which Kulthau characterised as the "move from ambiguity to specificity, or what I call uncertainty to understanding" (Kuhlthau, 1993, 340). We aim to address that gap with the inclusion of the third type of measurement, social network analysis.

\subsubsection{Social network analysis}

To analyze the social component of usage, we constructed a social network model using a mixed methods approach by transforming qualitative Gimlet entries into quantitative measurements of relationships between reference staff and electronic resources through coding. We began by exporting one year's worth of Information Desk transactions logged in Gimlet into an Excel spreadsheet. Of all of the transactions logged that year - a total of 11,444 - 4,024 of those were tagged by Information Desk staff as reference interactions. The others were tagged by Information Desk staff as policy $(669)$, directional $(2,120)$, or technical $(4,542)$. Since the purpose of this research is to describe the interactions between Information Desk staff and patrons regarding electronic resources only the reference transactions are considered in the analysis.

We trained a library student employee to review each of the 4,024 Gimlet entries that were marked as reference interactions. The student read the transcription of the questions, as well as the answers the Information Desk staff gave to the patron and determined if an electronic resource was mentioned during each encounter. For this analysis we define an electronic resource as: 
- a single e-journal or collection of e-journals;

- an e-book or collection of e-books;

- databases;

- portals - pointers to other electronic resources.

The student referred to a list of possible electronic resource titles, as well as their common names and acronyms, to determine if the interaction mentioned an electronic resource. If the student determined that an e-resource was mentioned, she tagged that interaction with a 1; if an e-resource was not mentioned, she tagged that interaction with a 0 . If the interaction did mention an electronic resource, she marked a cell in a column for the title of that resource. All the student's work was reviewed by the first author and any discrepancies were discussed and consensus reached about how to tag the interaction. Of the 4,024 reference transactions, 1,548 mentioned an electronic resource and 137 unique electronic resources were mentioned. See Appendix A in the Supplementary File for the list of electronic resources and the number of times they were each mentioned.

The list of electronic resources in Appendix A includes both databases and the platforms from which the databases are accessed. This is a consequence of the data entered into Gimlet to describe an Information Desk interaction. If the only data entered into the system was "EBSCO," for example, and if it was not possible to determine which specific database on the EBSCO platform was suggested, we coded the encounter with the platform name. As a result, the network diagrams presented in the findings include both database names and platform names.

We used UCINET (Borgatti et al., 2002) to analyze the tagged Gimlet data, using only the 1,548 reference interactions that included the mention of an electronic resource. Our data set contained the name of the Information Desk staff person who suggested the resource and the titles of the resources suggested at each encounter.

\subsection{Social network analysis findings}

We used social network analysis to explore the gap between proxy server hits and COUNTER-recorded downloads.

We used NetDraw (Borgatti, 2002) to create a two-mode network visualization, in which one node is the staff person name and the other node is the title of an electronic resource. Figures 6-9 show the relationship between Information Desk staff and electronic resources. The spring embedding layout algorithm was used and is explained in more detail, together with other aspects of two-mode concepts, by Borgatti ([2007]). 
Figure 6 shows the universe of interactions which mention an electronic resource, with the circles representing the Information Desk staff who recommended the electronic resources. The electronic resources are represented as boxes. A line connecting a circle to a square signifies that the member of staff recommended that resource at least once. The thicker the line, the more often that resource was recommended. The circles which are more central in the picture represent the people who suggested the most electronic resources and the widest variety of resources. The boxes which are more central in the picture represent electronic resources that were most frequently referred to and which have the largest number of staff referring to them.

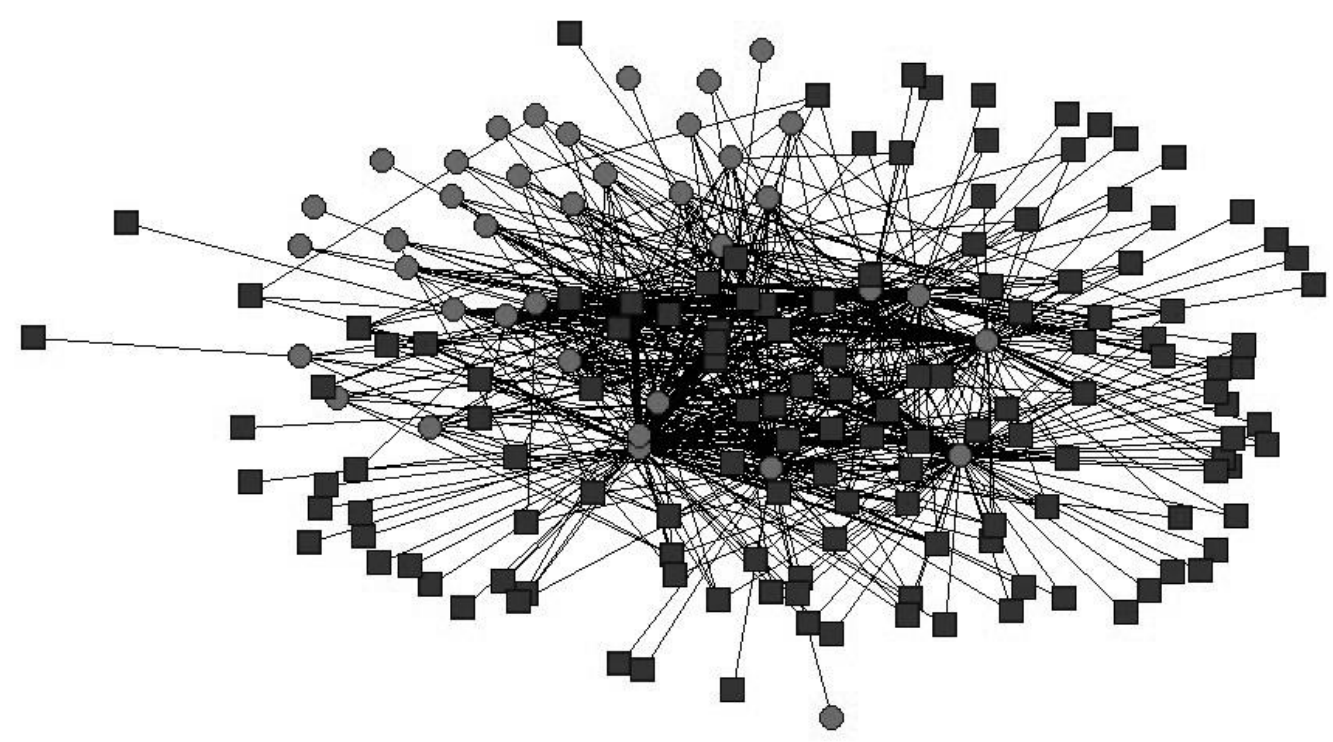

Figure 6: Interactions between staff and electronic resources.

To better understand which Information Desk staff suggested which kinds of electronic resources, Figure 7 shows the relationships between groups of Information Desk staff and the kinds of electronic resources suggested. The diagram features four different types of Information Desk staff:

- white circles represent Reference department librarians;

- light grey circles represent non-Reference department librarians;

- black circles represent contract staff (night shift workers);

- dark grey circles represent student employees.

Figure 7 also differentiates between a portal, an access point that leads to a multitude of electronic resources, represented by a white square, and a single database, represented by a light grey square. 


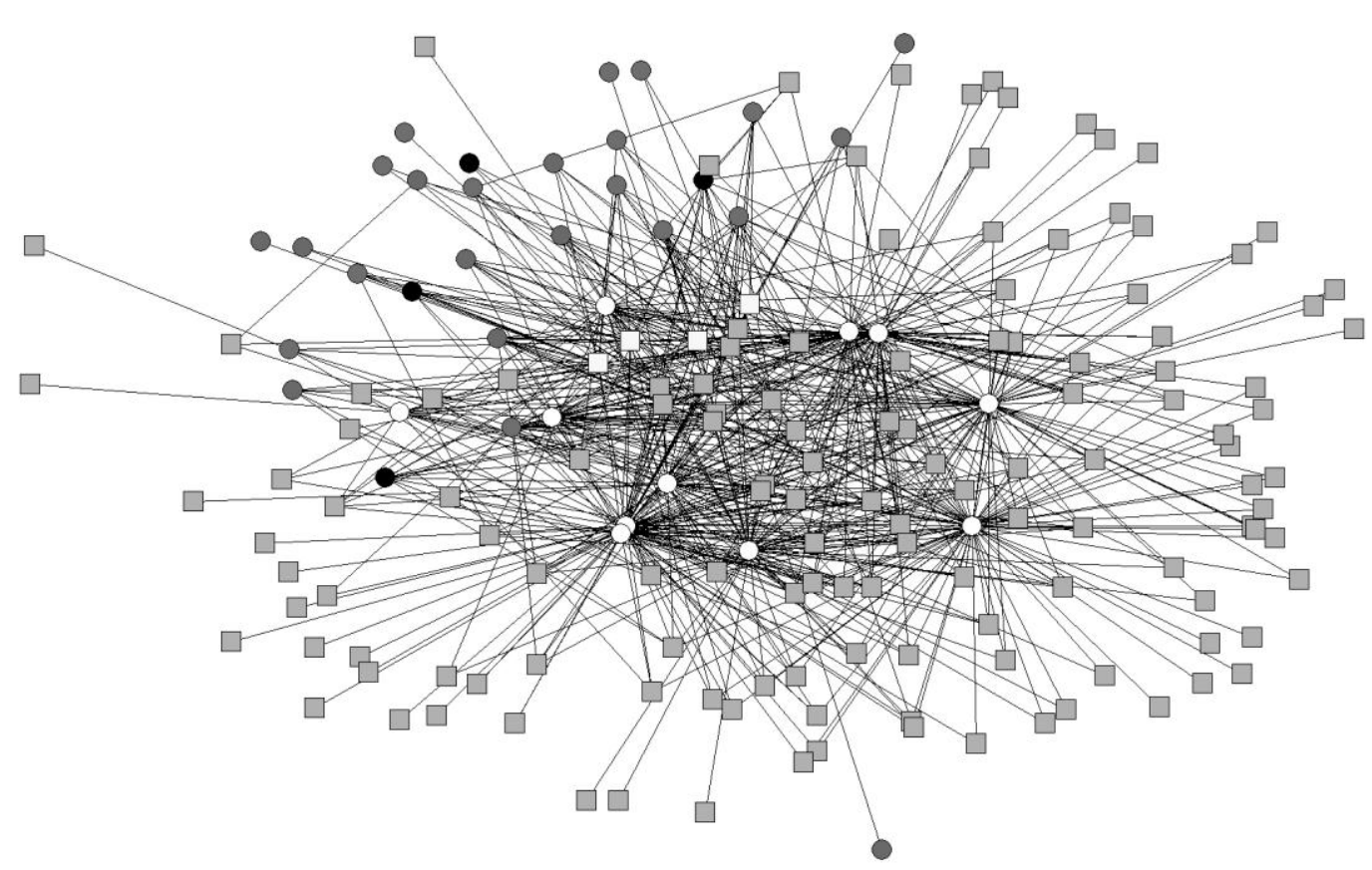

Figure 7: Suggestions by type of staff, type of resource.

As might be expected, the Reference department librarians (white circles) are central to the network, demonstrated by their presence in the centre of the diagram and by the thick lines which represent the number of times they suggested electronic resources, as well as the variety of resources suggested. Portals (white squares) are also central to the network. The portals included in this analysis are:

- LibGuides, the library's subject guides;

- the A-Z journal list that includes all the library's print and electronic journal titles;

- the research databases page;

- OneSearch+, the library's discovery layer.

To examine whether there is a clear core set of Information Desk staff and electronic resources, we eliminated peripheral electronic resources and Information Desk staff with very few connections to the rest of the network. We defined peripheral electronic resources as those that were suggested only three times or fewer and defined peripheral Information Desk staff as those who only suggested three or fewer resources during the timeframe analyzed. Excluding these peripheral resources and staff, Figure 8 shows the remaining interactions. Reference department librarians (white circles) remain core to the network, as do the library's portal resources (white squares). We can describe the staff and electronic resources represented in Figure 8 as core staff / resources. 


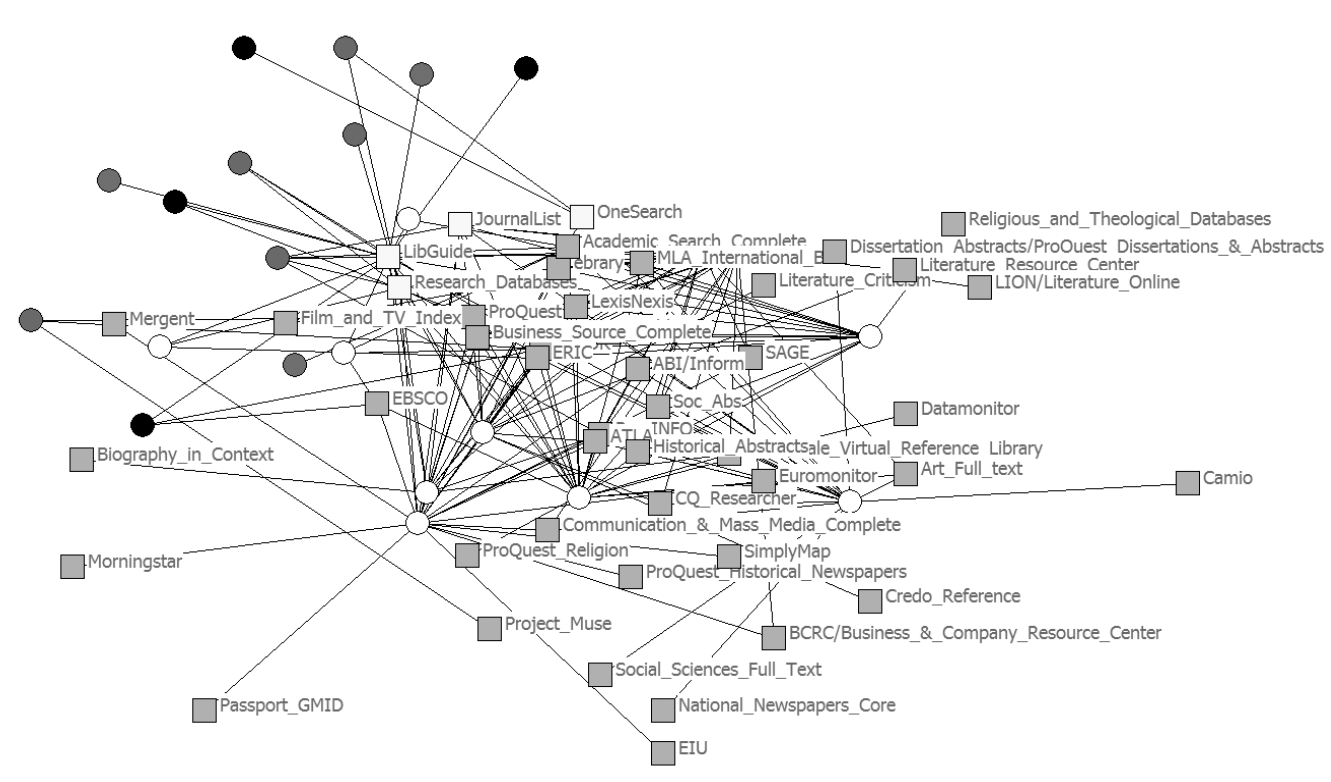

Figure 8: 4 or more suggestions by type of staff, type of resource.

When we examine the electronic resources mentioned during a reference interaction we find that there are many that co-occur; that is, more than one resource is suggested during a single reference interaction. In fact, in this data set there are only 11 out of 137 total electronic resources that are mentioned as the only resource during a reference interaction. The rest of the time the Information Desk staff suggested a suite of e-resources to assist in resolving an information

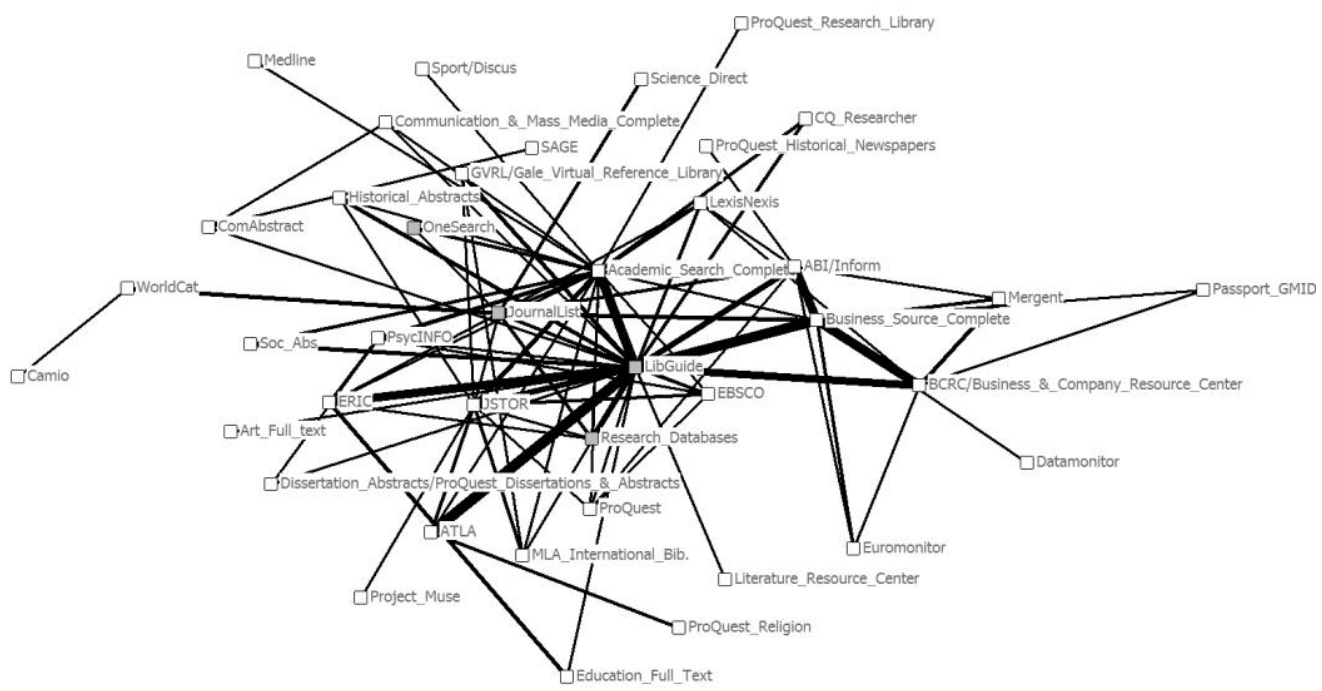

Figure 9: Suggestions of multiple resources. 
need. Figure 9 shows a one-mode network diagram only including electronic resources, which were recommended together 4 or more times. For example, in this data set when Business Source Complete was suggested, ABI/INFORM was also suggested, 27 times.

\section{Discussion}

Knowledge creation is not confined to an individual, rather it is a social process between individuals, groups and organisations.

(Zheng and Yano, 2007, 5)

By viewing the reference interactions data through the lens of social network analysis we find the following benefits:

1. We are provided new views of the use of electronic resources, especially the social component.

2. We can see which resources were not suggested over the course of one year.

3. We have evidence that e-resources are suggested and used in concert. There are central resources that are mentioned together, instead of a single eresource being suggested alone to resolve an information need.

The decision to use the social network analysis as a feature of this research stemmed from our reading about the information seeking process and our interest in better understanding the relationship between a patron and library staff in their processes of "finding." Our focus on Information Desk staff and the electronic resources they suggest has informed us about how future interactions at the Information Desk may be shaped.

A clear limitation of this research is that the data points cannot provide a whole picture of use, but rather provide a possible view of the process of information seeking. As Wilson notes, there are barriers to the information-seeking process that cannot be addressed with our existing data set, such as personal, role-related, or environmental factors (Wilson, 1999, 252). This research contributes to the literature about information seeking behaviour by examining the interactions of expert guides and the electronic resources they suggest, in response to a stated information need.

\section{Future research, future practice}

The benefits of viewing reference interactions using social network analysis suggest possible areas for future research.

We may consider expanding the data set to cover more years, to look at which electronic resources are suggested over time. This kind of longitudinal data could provide the library with evidence to inform policy as well as useful research material. We could suggest a new collection development policy to examine those 
electronic resources not mentioned during an Information Desk interaction, in order to determine if those resources are still desirable for their subject area specialty. This could become a multi-pronged approach to reaching decisions about renewing electronic resource subscriptions, based on more than just the COUNTER statistics. This approach can tell us, for example, if an electronic resource is not suggested during reference interactions but is still receiving hits recorded in the proxy server data. The COUNTER statistics may show that patrons are indeed requesting full-text downloads from a resource and that the lack of Information Desk recommendation of a resource does not hinder information seekers from finding and using its content. Discovering why this may occur could provide a fruitful topic for further research which could include direct interaction with information seekers.

We know that electronic resources are mentioned in places and times other than during a reference transaction, but these are generally not recorded. Some examples of other sources of electronic resource suggestions include:

\section{- LibGuides;}

- instruction workshops;

- tutoring sessions;

- faculty syllabi;

- blog or Facebook posts;

- other offices on campus, such as the Academic Resource Centre and the Student Innovation Centre.

The mentions of electronic resources in these examples are currently ad hoc but could be systematised in future research for a more comprehensive understanding of the relational nature of electronic resources.

The formalised mechanisms for suggesting electronic resources noted above still do not fully describe the universe of possible suggestions. We can imagine scenarios which are uncountable for practical purposes, including:

- the suggestions from peers via word-of-mouth;

- $\quad$ suggestions from professional or personal connections via social network tools such as Twitter, Facebook, and blogs, although progress is being made in this area through the development of Altmetrics;

- through linked data in web browsers such as Google.

The use of social network analysis also provides some practical insights that may be utilised in the initial training and ongoing support of Information Desk staff. As shown in Figure 9, often more than one electronic resource is suggested to 
resolve an information need. It may be assumed that Reference Department librarians would be able to identify the most and widest variety of electronic resources available at the library. A list or chart of electronic resources could be developed to assist non-Reference Department librarians to match this diversity of e-resource suggestions during an Information Desk encounter. The chart could contain the resources identified in Figure 9, noting for example, that if Business Source Complete is suggested one might also suggest ABI/INFORM. The chart could be based on the resources identified in this research as co-occurring.

These findings could also be used for collection development purposes by identifying the electronic resources which were not mentioned once during the year. Those resources could be prioritized and selected for marketing for a set period of time. Usage statistics for those resources could be examined at the outset and during that marketing period to determine if they are being used enough to justify a renewed subscription. It may be that even after the resource is identified and prioritised to be actively suggested at the Information Desk, it will remain insufficiently used (based on a pre-determined threshold), leading to the cancellation of that subscription.

\section{Conclusion}

Although this research was initially intended to be conceptual in nature the resulting analysis suggests multiple practical implications for the daily operation of an academic library, including for the training and ongoing support of Information Desk staff, as well as for collection development and marketing. We believe that the flexibility inherent in social network analysis makes it a valuable tool for examining relational aspects of the library.

In this article we have described a view of the information seeker's path from "finding" to "found", by inserting a social network analysis perspective into the traditional models of seeking. Understanding that the process of information seeking can have a social / relational component, and that the process may include an expert guide who can suggest specific electronic resources that may fulfil an information need, provides a fuller picture of the information seeking process. This research has used the accepted model of expert-mediated searching and provides insight into the role that the expert plays by examining the electronic resources s/he suggests in a reference interaction.

\section{References}

Bates, M. J. (1989) The design of browsing and berrypicking techniques for the online search interface. Online Review, 13(5), 407-424.

Borgatti, S. P. (2002) NetDraw software for network visualization. Lexington: Analytic Technologies.

Borgatti ([2007]) 2-Mode Concepts in Social Network Analysis [online]. URL: http://steveborgatti.com/papers/2modeconcepts.pdf [accessed 1.11.14]. 
Borgatti, S. P., Everett, M. G. and Freeman, L. C. (2002) UCINET for Windows: Software for social network analysis. Harvard: Analytic Technologies.

Contractor, N. S., Monge, P. R. and Leonardi, P. M. (2011) Multidimensional networks and the dynamics of sociomateriality: Bringing technology inside the network. International Journal of Communication, 5, 682-720.

COUNTER (2008) The COUNTER Code of Practice [online]. URL: http://www.projectcounter.org/r3/Release3D9.pdf [accessed 8.11.14].

COUNTER (2014) COUNTER [online]. URL: http://www.projectcounter.org/ [accessed 8.11.14].

Dervin, B. (1977) Useful theory for librarianship: Communication, not information. Drexel Library Quarterly, 13(3), 16-32.

Dervin, B. and Nilan, M. (1986) Information needs and uses. In: Williams, M. E. (ed.) Annual Review of Information Science and Technology. White Plains: Knowledge Industry Publications.

Gimlet (2014) Staff your desk wisely [online]. URL: http://gimlet.us [accessed 1.11.14].

Grogg, J. E. \& Fleming-May, R. A. (2010) Chapter 1: Assessing use and usage. Library Technology Reports, 46, 5.

Kuhlthau, C. C. (1993) A principle of uncertainty for information seeking. Journal of Documentation,49, 339-355.

Kuhlthau, C. C. (2004) Seeking meaning: A process approach to library and information services. 2nd ed. Westport: Libraries Unlimited.

Marchionini, G. (1995) Information seeking in electronic environments. New York: Cambridge University Press.

NISO (2013) Standardized Usage Statistics Harvesting Initiative (SUSHI) National Information Standards Organization [online]. Baltimore: National Information Standards Organization. URL: http://www.niso.org/workrooms/sushi [accessed 1.11.14].

Talia, S. (2002) Information sharing in academic communities: Types and levels of collaboration in information seeking and use. New Review of Information Behaviour Research, 3, 143-160.

Tucker, C. (2009) Benchmarking usage statistics in collection management decisions for serials. Journal of Electronic Resources Librarianship, 21, 48-61.

Wilson, T. D. (1981) On user studies and information needs. Journal of Documentation, 37, 3-15. 
Wilson, T. D. (1999) Models in information behaviour research. Journal of Documentation, 55, 249-270.

Zheng, Y. \& Yano, Y. (2007) A framework of context-awareness support for peer recommendation in the e-learning context. British Journal of Educational Technology, 38, 197-210.

\section{Acknowledgement}

We acknowledge the assistance of Alyssa Veneza, who assisted in the coding of the Gimlet data.

Preliminary results of the work represented here were presented at the 2013 Qualitative and Quantitative Methods in Libraries conference (Rome, Italy).

\section{Open access and copyright}

Library and Information Research is an open access journal. A freely available copy of this paper may be downloaded from the journal's website: http://www.lirgjournal.org.uk.

Copyright and associated moral rights in works published in Library and Information Research are retained by the author(s) but this paper may be used freely, with proper attribution, in educational and other non-commercial settings. 